\title{
Correction to: A Process Evaluation of a Substance Use Program for Pregnant Women: Lessons Learned from the Field
}

Jessica L. Chou ${ }^{1}$ - Bertranna A. Muruthi ${ }^{2}$ Maliha Ibrahim ${ }^{1} \cdot$ Emily Janes $^{3}$.

Lara B. Pennington $^{4} \cdot$ Rosalie Seiler ${ }^{5} \cdot$ Katherine Pierce $^{6} \cdot$ Debra Zand $^{6} \cdot$ Dara Herbert $^{1}$

Published online: 7 August 2020

(C) Springer Science+Business Media, LLC, part of Springer Nature 2020

\section{Correction to: International Journal of Mental Health and Addiction. https://doi.org/10.1007/s11469-020-00374-1}

The middle initial of coauthor Bertranna A. Muruthi was incorrectly given as "M." in this article as originally published.

The original article has been corrected.

Publisher's Note Springer Nature remains neutral with regard to jurisdictional claims in published maps and institutional affiliations.

The online version of the original article can be found at https://doi.org/10.1007/s11469-020-00374-1

Jessica L. Chou

jlc563@drexel.edu

1 Department of Counseling and Family Therapy, Drexel University, Chou, 1601 Cherry Street, Philadelphia, PA 19103, USA

2 Department of Counseling Psychology and Human Services, University of Oregon, Eugene, OR, USA

3 Marriage and Family Therapy Program, Virginia Tech Northern Virginia Center, Idylwood, VI, USA

4 Anthropedia Foundation, Saint Louis, MO, USA

5 Queen of Peace Center, Saint Louis, MO, USA

6 General Academic Pediatrics, Saint Louis University School of Medicine, St. Louis, MO, USA 